\title{
Non-invasive Prenatal Diagnosis of $\beta$-Thalassemia by Detection of the Cell-Free Fetal DNA in Maternal Circulation
}

\author{
Hasnaa Ahmed Abo- El Wafa, Eman Hassan Ali, Mohammed Hamdy \\ Mahmoud, Shimaa Anwar Rashed, Nesma Mokhtar Ahmed, Sara Talal \\ Mahmoud \\ Departments of Clinical and Chemical Pathology, Faculty of Medicine- Sohag \\ University
}

Corresponding Author: Sara Talal Mahmoud

\begin{abstract}
:
$\beta$-thalassemia is one of the most frequent autosomal recessive diseases that has a high recurrence in people of the Mediterranean zone, the Middle East, India, the Far East, Tropical Africa, and the Caribbean. Parents who are both carriers for $\beta$-thalassemia have a $25 \%$ danger to give a child with $\beta$-thalassemia major, a disorder that requires a longlasting blood transfusion and costly iron-chelation treatment. The most accessible strategies for pre-birth diagnosis are chorionic villus sampling (CVS) somewhere in the range of 11 and 14 weeks and amniocentesis following 15 weeks and both are invasive procedures and cause dangers to the fetus and mother, having a danger of abortion 1 in 100-200 and 1 in 200-400, respectively. The accuracy of these methods is estimated to be $98-99 \%$. Cell-free fetal DNA (cff-DNA) can be found in maternal plasma following 18 days from fertilized egg implantation in Pregnancies after lab conception and resembles extracellular DNA. The discovery of cff-DNA in maternal plasma has led to the evolution of noninvasive prenatal diagnosis. Some genomic loci of cff-DNA show methylated sequences unique in relation to circling maternal DNA, this trademark can be utilized to evaluate and demonstrate the presence of fetal DNA during pregnancy, independent of the sex of the embryo. the two major limitations for non-invasive prenatal diagnosis (NIPND) are the small amount of cff-DNA in maternal blood and its coexistence with maternal free DNA.we study investigations used in the detection of inherited mutation of $\beta$-thalassemia in maternal plasma during pregnancy using cell-free fetal DNA and evaluate the diagnostic test performance of cff-DNA for this issue.
\end{abstract}

\section{INTRODUCTION}

$\beta$-thalassemia is one of the most frequent autosomal recessive diseases that has a high recurrence in people of the Mediterranean zone, Middle East, India, the Far East, Tropical Africa, and the Caribbean (1). Parents who are both carriers for $\beta$-thalassemia have a $25 \%$

danger to give a child with $\beta$-thalassemia major, a disorder that requires longlasting blood transfusions and costly iron-chelation treatment (2). The most accessible strategies for pre-birth diagnosis are chorionic villus sampling (CVS) somewhere in the range of 11 and 
14 weeks and amniocentesis following 15 weeks and both are invasive procedures and cause dangers to the fetus and mother, having a danger of abortion 1 in 100-200 and 1 in 200-400, respectively (3). The accuracy of these methods is estimated to be $98-99 \%$ (4). Cell-free fetal DNA (cff-DNA) can be found in maternal plasma following 18 days from fertilized egg implantation in Pregnancies after lab conception and resembles extracellular DNA (5). The discovery of cff-DNA in maternal plasma has led to the evolution of noninvasive prenatal diagnosis (6). Some genomic loci of cff-DNA show methylated sequences unique in relation to circling maternal DNA, this trademark can be utilized to evaluate and demonstrate the presence of fetal DNA during pregnancy, independent of the sex of the embryo (7). the two major limitations for (NIPND) are the small amount of cff-DNA in maternal blood and its co-existence with maternal free DNA (8).

\section{AIM OF THE WORK}

The purpose of the study to:

- evaluate the diagnostic test performance of cell-free fetal DNA for this issue.

- To study investigations used in the detection of inherited mutation of $\beta$ thalassemia in maternal plasma during pregnancy.

\section{Epidemiology and the global burden} of $\beta$-thalassemia:

The all-out yearly frequency of symptomatic $\beta$ - thalassemia patients is evaluated to be 1 of every 10,000 patients in the European Union and 1 of every 100,000 all through the world (9).

Pathophysiology of $\boldsymbol{\beta}$-thalassemia:

When Unstable globin chain tetramers precipitate it undergoes oxidation into methemoglobin leading to separation of heme from globin. The free iron released from heme in the erythroid cells catalyzes the formation of reactive oxygen radicals leading to oxidation of membrane proteins, structural membrane defects, and exposure of red-cell senescence antigens such as phosphatidylserine causing premature cell death within the bone marrow (ineffective erythropoiesis) or peripheral circulation (hemolysis ((10).

In non-transfused patients, Ineffective erythropoiesis results in increased iron absorption causing iron overload mediated by the hepcidin hormone. An erythroid factor has thought to sense the liver the need of iron for the incoming red blood cells. This factor would be produced by erythroid cells, especially under the condition of ineffective erythropoiesis, and acts to suppress hepcidin synthesis in the liver, leading to increased intestinal iron absorption and increased release of recycled iron from the reticuloendothelial system (11).

\section{Clinical phenotypes of $\beta$-thalassemia:}

$\beta$-thalassemia can be divided into three main clinical phenotypes: thalassemia major (TM), thalassemia trait (TT) and thalassemia intermedia (TI). TM is a severe form that requires transfusions beginning from infancy for survival, whereas TT is usually asymptomatic. TI is used to indicate a clinical condition of intermediate severity between TT and TM, which involves a wide phenotypic spectrum ranging from mild anemia to more severe anemia requiring only occasional blood transfusions if needed (12).

Molecular genetics and genetic m0difiers of $\beta$-thalassemia:

The $\beta$-globin gene (HBB) and normal expression: 
$\beta$-globin encrypted by a gene found in a group with other $\beta$-like genes on chromosome 11 (11p 15.15) (13). This group contains five genes, $\varepsilon$ (HBE), $\mathrm{G} \gamma$ (HBG2), A $\gamma$ (HBG1), $\delta$ (HBD), and $\beta$ (HBB), which organized in the request of their appearance to deliver changed $\mathrm{Hb}$ tetramers: embryonic (Hb Gower-1

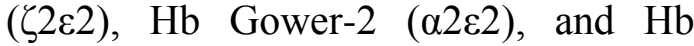
Portland ( $(2 \beta 2))$, fetal $(\alpha 2 \gamma 2)$, and adult $(\mathrm{HbA}, \alpha 2 \beta 2$ and $\mathrm{HbA} 2, \alpha 2 \delta 2)$ (14).

HBB directed by a neighboring $5^{\prime}$ promotor in which TATA, CAAT, and copied CACCC boxes are found it ranges $1.6 \mathrm{~Kb}$ and contains three exons and both $5^{\prime}$ and $3^{\prime}$ untranslated districts (UTRs)(15).

Articulation of the globin genes is subject to neighborhood arrangements and the upstream $\beta$-globin locus control area ( $\beta$-LCR) which comprises five Dnase 1 overly sensitive (HS) locales (assigned HS1 to HS5) appropriated somewhere in the range of 6 and $20 \mathrm{~kb} \mathrm{5}^{\prime}$ of HBEgene.There is a one HS site at roughly $20 \mathrm{~kb}$ downstream of $\mathrm{HBB}$ quality (16).

All these administrative areas tie various key erythroid-explicit interpretation factors, remarkably GATA-1, GATA-2, NF-E2, KLF1 (otherwise called EKLF), and scales well as different co-fact0rs (e.g., FoG, p300), and factors that are more ubiquitous in their tissue conveyance, for example, Sp1(13).

\section{Molecular pathology of $\beta$-thalassemia:}

More than $300 \beta$-thalassemia alleles have now been depicted yet just around forty records for $90 \%$ or a greater amount of the $\beta$-thalassemias worldwide(17).

Non-deletion $\beta$-thalassemia:

These include Single base substitutions, little additions or erasures of one to a couple of bases situated inside the gene or its quick flanking arrangements. They down manage the $\beta$-globin quality by means of pretty much every known phase of gene articulation, from interpretation to RNA handling and interpretation of $\beta$-globin mRNA. Around half of the non-deletional changes totally inactivate the $\beta$-quality prompting no $\beta$-globin generation coming about in $\beta 0$ thalassemia (18).

Deletions causing $\beta$-thalassemia:

$\beta$-thalassemia is seldom brought about by one of 15 erasures limited to the HBB gene, of which two evacuate the $3^{\prime}$ end of the quality however leave the $5^{\prime}$ end flawless. The size of these cancellations vary generally (from $290 \mathrm{bp}$ to $>67 \mathrm{~kb}$ ) yet in like manner they expel an area in the $\beta$ promotor (from position -125 to +78 with respect to the mRNA CAP site) which incorporates the CACCC, CCAAT, and TATA elements. They are amazingly uncommon, however of specific clinical intrigue since they are related to a bizarrely large amount of $\mathrm{HbA} 2$ and $\mathrm{HbF}$ in heterozygotes. However, the expansion in $\mathrm{HbF}$ is sufficient to make up for the total nonappearance 0 f HBA in homozygotes for these cancellations, these erasures result in $\beta 0$ thalassemia(19).

Dominantly inherited $\beta$-thalassemia :

As opposed to the basic $\beta$-thalassemia alleles that are acquired regularly as Mendelian recessives, a few types of $\beta$ thalassemia are predominantly acquired, in that legacy of a solitary duplicate of the $\beta$-thalassemia allele brings about clinical disease. Carriers have moderate to serious paleness, splenomegaly and the signs $0 \mathrm{f}$ heterozygous $\beta$-thalassemia raised $\mathrm{HbA} 2$ and imbalanced globin chain union (20).

Unusual causes of $\beta$-thalassemia:

These changes incorporate those in translation elements and chromatinrelated components, and in interpretation 
factors that explicitly influence the erythroid genealogy. A few changes influence articulation of $\alpha$ - globin (eg, ATRX30), while others for the most part influence $\gamma$-globin or $\beta$-globin articulation (eg, GATA1 and KLF1) (21).

\section{Genetic modifiers of $\beta$-thalassemia:}

Many hereditary modulators and cis-administrative components engaged with the control of human fetal hemoglobin $(\mathrm{HbF})$, and accompanying $\alpha$-thalassemia have been recognized as ameliorators of $\beta$ - thalassemia so, individuals with indistinguishable $\beta$ thalassemia genotypes can display variable clinical severities (22).

\section{Management of $\boldsymbol{\beta}$-thalassemia:}

A)Diagnosis of $\beta$-thalassemia:

\section{Clinical diagnosis:}

TM is suspected in babies under 2 years of age with serious microcytic anemia, hepatosplenomegaly, and slight jaundice. TI is suspected in people who present at a later age with comparable yet milder clinical side effects (15).

\section{Laboratory diagnosis:}

\section{- Complete blood count:}

In spite of the fact that the hypochromic microcytic pallor saw in thalassemias likewise happens in iron inadequacy, iron lack anemia is generally associated with a diminished RBC number and expanded red cell distribution width (RDW), while thalassemia tends towards an expanded RBC number and ordinary RDW (23).

\section{2)Protein-based diagnostic modalities:}

The most popular electrophoretic technique now being used is isoelectric focusing, which has to a great extent supplanted cellulose acetate alkaline electrophoresis. This strategy effectively isolates the most well-known hemoglobins, including hemoglobin A1, hemoglobin $\mathrm{F}$, and hemoglobin $\mathrm{A} 2$ and the frequent variations hemoglobins $\mathrm{S}$ and $\mathrm{C}$. Electrophoresis utilizing citrate agar at $\mathrm{pH} 6.2$ permits hemoglobin $\mathrm{S}$ or hemoglobin $\mathrm{C}$ to be recognized from different variations that settle correspondingly by isoelectric focusing(24).

Considerably better separation is presently achieved utilizing capillary zone electrophoresis, which can, for instance, separate hemoglobin $\mathrm{E}$ from hemoglobin A2, something impractical with the methods referenced above or with high-pressure liquid chromatography (HPLC). Capillary zone electrophoresis can possibly supplant more established electrophoresis techniques in numerous research centers sooner (25).

\section{3)Molecular diagnostic techniques:}

Since most $\beta$-thalassemias are because of point transformations, Sanger sequencing is the most common current technique to recognize every conceivable change in an individual (24).

Another method is to use allele-specific PCR to detect specific genetic changes, as described for common Southeast Asian and Indian mutations (26).

B) Screening and reduction of $\beta$ thalassemia :

Due to the wellbeing burden, many nations with a high predominance of $\beta$ thalassemia are focused on the usage of control measures, including transporter screening and pre-birth diagnosis.Couples with a family ancestry of thalassemia wanting to have youngsters are encouraged to have hemoglobinopathy screening, trailed by fitting hereditary directing. The danger of passing on major thalassemia ought to be clarified, and the data gave ought to 
be gone for supporting choices on propagation (27).

Non-Invasive Prenatal Diagnosis Using Cell-Free Fetal DNA: Cell-free fetal DNA (cff-DNA):

Cell-free DNA in maternal plasma is prevalently maternal in a source, with the fetal part, changing both between and during pregnancies, frequently expanding as pregnancy advances and impacted by an assortment of variables including maternal smoking, maternal weight, and pre-eclampsia (28).

It is significant that fetal DNA can be recovered non-intrusively from three sources - cff-DNA in maternal blood, circling fetal cells in maternal blood and transcervical trophoblastic cells (29).

The normal size of cff-DNA is known to be under $300 \mathrm{bp}$, rather than the maternal cf-DNA parts, which are noticeably longer (30).

The extent of cff-DNA relative to maternal cell-free DNA levels in a blood test is known as the fetal portion (31).

The fetal portion is $3 \%$ to $13 \%$ and It is presently realized that the fetal part increases step by step all through pregnancy and after that rises remarkably following 20 weeks (32). Overestimates of the fetal portion may prompt false-negative outcomes, while depreciating of fetal division may make appropriate samples be rejected (28).

Non-invasive prenatal diagnosis:

Recognizable proof of cf-DNA in the maternal serum arose a vigorous examination concerning its beginning and potential clinical applications. Noninvasive pre-birth testing or cf-DNA screening accordingly developed as an amazing screening device for the normal autosomal and sex chromosome aneuploidies (33).

The advancement of next-generation sequencing (NGS) and remarkably desk- top sequencers lead to expansion of NIPD to incorporate the presentation of bigger gene strategies and increasingly complexed hereditary investigation for finding of recessive, $\mathrm{X}$-linked and dominant conditions acquired from the mother (34).

\section{Non-invasive prenatal diagnosis of} monogenic disorders:

Besides aneuploidy screening and sex identification, cff-DNA has been employed for pre-birth analysis of fetal blood typing and autosomal predominant, autosomal latent, and Xconnected scatters.

cf-DNA methods utilized for the recognition of single-gene disorders require more advanced methodologies than those utilized for aneuploidy screening. The utilization of cf-DNA for detection of the single-gene disorder is a developing innovation, and its application is constrained right now. A few scientists advance the idea that, rather than aneuploidy screening where positive outcomes require further interfering testing to affirm a finding, cfDNA testing for single-gene disorder might be considered diagnostic(35).

\section{A)Detection \exclusion of paternally inherited mutations:}

A finding of monogenic disorders has concentrated on ways to detect fatherly way acquired fetal genetic defects absent from the maternal genome (36).

A guideline of this system has been applied for NIPT of $\beta$-thalassaemia, cystic fibrosis and inborn adrenal hyperplasia $(\mathrm{CAH})$. The determination dependent on the absence of finding of the fatherly acquired genetic changes further requires to build up a positive control test, for instance, by focusing on other a fatherly way acquired allele, 
which would affirm the existence of fetal DNA in maternal plasma (37).

B)Detection of maternally inherited alleles and alleles shared by both parents :

The researchers had to develop more sophisticated strategies to assess the fetal mutations in maternal plasma that share the same genetic identity between the mother and the fetus. These approaches were helped by technological advances, such as massively parallel sequencing (MPS) or digital PCR (dPCR), offering a sensitive and precise measurement of circulating plasma DNA. These enabled the analysis of fetal mutations inherited from the mother despite the fact that they are masked in the background of identical DNA sequences of maternal origin (38).

The analysts needed to grow increasingly complex techniques to detect the fetal changes in maternal plasma that offer a similar hereditary character between the mother and the baby. These methodologies were helped by innovative advances, for example, massively parallel sequencing (MPS) or digital PCR (dPCR), offering a delicate and exact estimation of circling plasma DNA. These capable the examination of fetal changes acquired from the mother in spite of the way that they are hidden by indistinguishable DNA arrangements of maternal source (36). The next two sections introduce the basic principles of the two robust approaches developed for NIPT of monogenic diseases.

The relative mutation dosage approach :

By utilizing dPCR for maternal plasma DNA investigation, the relative mutation dosage (RMD) approach could evaluate maternally acquired fetal transformations for NIPT of monogenic diseases (38).
The justification lies in the recognizable proof of slight quantitative changes of the overall extents of the altered and wild-type alleles brought about by the extra commitment of maternally acquired fetal alleles in maternal plasma. In fact,one could recognize a decent proportion of the altered and the wildtype alleles (1:1 allelic proportion) in the plasma of non-pregnant lady heterozygous at the locus (i.e., having one altered and one wild-type allele) (38).

The RMD approach has been employed for the diagnosis of maternally acquired fetal genetic changes causing $\beta$ thalassemia (39), sickle-cell weakness (40), hemophilia (401) and methylmalonic acidemia (42).

The relative haplotype dosage approach (RHDo):

The recent sequencing advancements allow acquiring the entire mutational profile of the baby from maternal plasma, which opens new interesting chances to analyze for all monogenic illness by utilizing just a single hereditary test (43).

The single-nucleotide polymorphism (SNP) data recognized in the fatherly and maternal genomes encourages the understanding of DNA sequencing information for NIPT of monogenic illnesses. To begin with, the fatherly inheritance is derived through the identification of in a fatherly way acquired SNPs and additionally changes present in maternal plasma however missing from the mother's genome, which is heterozygous in the dad and homozygous in the mother (44). 


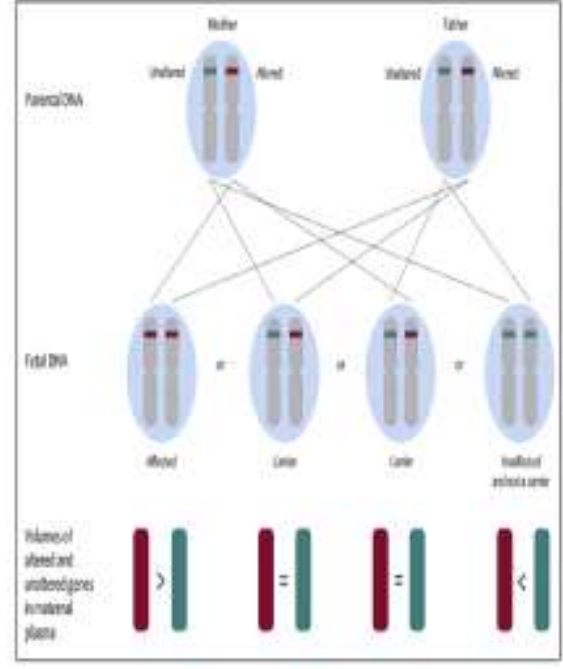

Figure 1:Illustration of relative mutation dosage: red represents the mutated allele and green the normal allele. The relative amount of mutation detected in maternal plasma indicates the genotype of the fetus(44).

Then again, the maternal inheritance is set up by questioning SNP markers as a progression of inheritance sequences, named haplotypes, chose from genomic districts physically connected to the change, for which the dad is homozygous and the mother is heterozygous. This system has been named as a relative haplotype dosage (RHDO) investigation and is influenced by the fetal DNA portion (36).

But, dissimilar to RMD that estimates the allelic changes related distinctly to one specific transformation or SNP, the RHDO approach counts maternal haplotypes. At that point, the power of such test increments by examining different SNP loci doled out to one haplotype. newly, rather than analyzing the entire genome, directed sequencing strategies enable one to examine just the targeted genomic loci (44).

The methodology utilized by Hui and colleagues utilizes a type of a direct haplotyping strategy, to be namely linked-read sequencing, in which parental haplotypes were resolved straightforwardly without a proband test (44).

Non-invasive prenatal diagnosis of $\beta$ thalassemia :

Thalassemias have been widely studied as a model for NIPT of monogenic diseases (37).

A) Exclusion of paternally inherited $\beta$ thalassemia mutations in pregnancies with parents carrying different mutations:

Chiu et al. researched the utilization of cf-DNA in maternal plasma in pregnancies in the danger of $\beta$ thalassaemia major. They effectively utilized an allele-specific real-time PCR for the analysis of the in a fatherly way acquired genetic changes, a 4-bp deletion at codon 41 and 42, CD 41/42 (-CTTT). The clinical importance of such a methodology was considerable, as the recognizable proof of babies that have not acquired the fatherly altered allele would get ride of the requirement for an invasive diagnosis in couples conveying diverse $\beta$-thalassemia changes (46).

\section{B)Exclusion of paternally inherited $\beta$ - thalassemia mutations shared by both Parents:}

When the couples are found to have a similar change, such a methodology probably won't be relevant because of the failure to recognize the maternal and fatherly alleles. In these clinical situations, the investigation of fatherly SNP markers solves the problem, in case that there is a lot of useful SNPs for which the mother is homozygous and the dad heterozygous can be acquired (43).

When contrasted with the mutationspecific measures, the SNP-based methodology can target the altered as well as the wild-type allele, if the 
linkage to the fatherly SNP has been built up from a family investigation. But, cautious selection of the methods is required so that the one-nucleotide changes between the maternal and fetal DNA in maternal plasma could be hardily investigated (36).

A size-based sorting of plasma cell-free DNA in agarose gel combined with concealment of maternal alleles utilizing a peptide-nucleic acid (PNA) clasp PCR has improved the affectability to recognize in a fatherly way acquired fetal point changes in couples conveying diverse $\beta$-thalassemia mutations(47).

Newly, Liu et al. have built up another improvement methodology for NIPT of in a fatherly way acquired fetal genetic changes causing $\beta$-thalassemia. They structured a primer-introduced restriction PCR (PIRA-PCR), which uses restriction digestion to specifically dispense with wild-type alleles for the recognition of fetal $\beta$-thalassemia changes in maternal plasma. This methodology relies upon a restricted number of restriction enzymes not reasonable for each transformation (48).

\section{C)Detection of maternally inherited $\beta$ - thalassemia mutations:}

To widen the range of pregnancies compliant to pre-birth testing for $\beta$ thalassemia utilizing maternal plasma DNA examination, one needed to create systems for the recognition of maternally acquired changes (36).

This objective has been accomplished by utilizing the RMD approach which allowed the recognizable proof of maternal changes in the HBB quality, CD 41/42 (-CTTT) and $\mathrm{HbE}(\mathrm{G}>\mathrm{A})$, in the plasma of pregnant transporters with normal homozygous male partners. The strategy accurately anticipated the fetal status in half of the cases, despite the fact that was not able to characterize 4 cases with fetal DNA portions lower than $10 \%$ and erroneously analyzed one case. The authors in this way built up another size-based methodology, called a digital nucleic acid size selection (NASS) to enhance fetal DNA sequences, which improved the RMD classification(49).

recently, Xiong et al. built up a focused on MPS way to identify the $\mathrm{HbE}$ and the four most regular $\beta$-thalassemia transformations found in southeast Asia. Eighty-three families with couples being transporters of the genetic changes were examined by utilizing three overlapping PCR amplicons for every one of the five analyzed changes to survey the existence of in a fatherly way acquired altered alleles in maternal plasma. The all affectability and explicitness for the discovery of fatherly transformations was $100 \%$ and $92.1 \%$, individually. The strategy was not appropriate to $33 \%$ of the pregnancies when the couples conveyed a similar change (39).

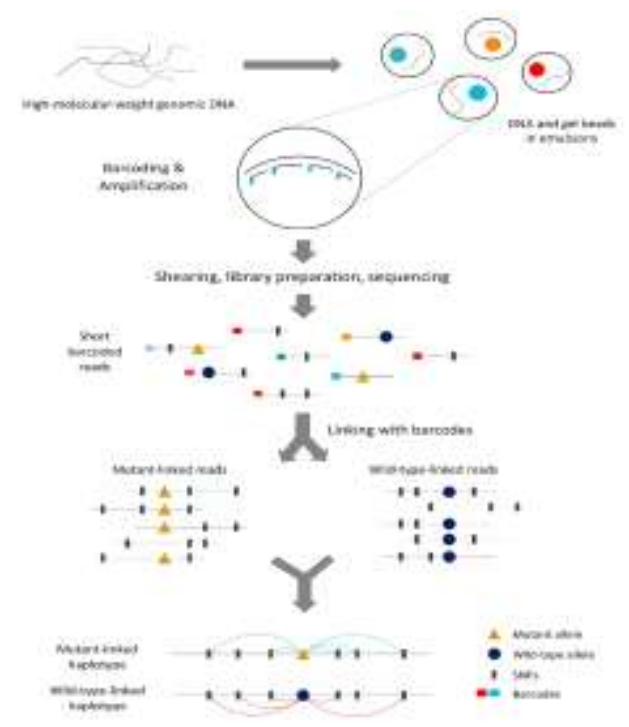

Figure 2:Schematic diagram for the process of linked-read sequencing (50). 


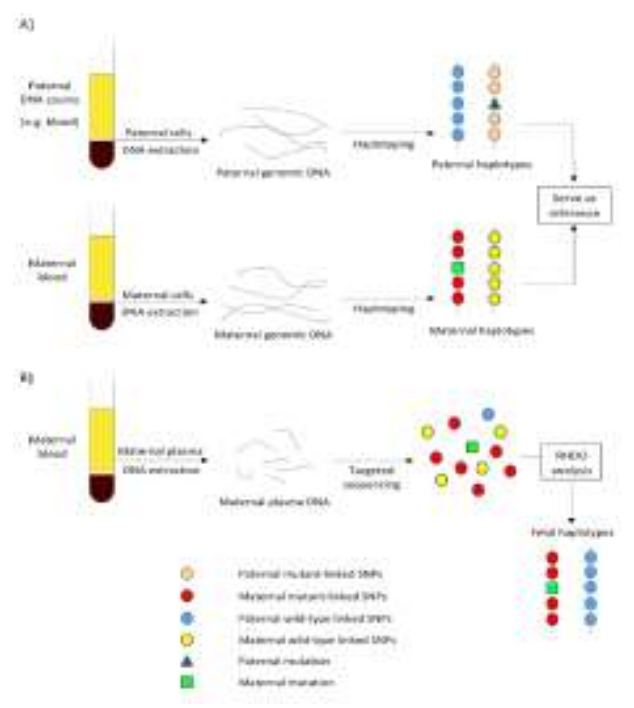

Figure 3: Schematic diagram for the general principle of NIPD of monogenic diseases(50).

\section{CONCLUSION}

detection of the paternal allele in maternal circulation by detection of cellfree fetal DNA is feasible. Nevertheless, more studies are required for developing and validating methods into efficient, precise, and reliable assays for detection paternally mutation in maternal plasma. A genome-wide map of the fetus has been generated for the parental haplotypes. Haplotype analysis and targeted next-generation sequencing provide NIPD for thalassemia by identifying paternal mutation in maternal plasma.

\section{REFERENCES}

1-Rosatelli MC and Saba L(2009): Prenatal Diagnosis of $b$ eta-Thalassemias and Hemoglobinopathies. Mediterr J Hematol Infect Dis;1(1): e2009011.

2-Chu T, Burke B, Bunce K(2009): A microarray-based approach for the identification of epigenetic biomarkers for the noninvasive diagnosis of fetal disease. Prenat Diagn;29:1020-30
3-Wah YM, Leung TY, Cheng YK(2016): Procedure-Related Fetal Loss following Chorionic Villus Sampling after FirstTrimester Aneuploidy Screening. Fetal Diag Ther Jul 12.

4-Papageorgiou EA and Patsalis PC (2012): Non-invasive prenatal diagnosis of aneuploidies: new technologies and clinical applications. Genome Med 4(5):46

5-Guibert J, Benachi A, Greville AG(2003): Kinetics of SRY gene appearance in maternal serum: detection by real-time PCR in early pregnancy after assisted reproductive technique. Hum Reprod; 18:1733-6

6-Go AT, van Vugt JM, Oudejans CB)2011): Non-invasive aneuploidy detection using free fetal DNA and RNA in maternal plasma: recent progress and future possibilities. Hum Reprod Update; 17 (3): 372-382.

7-Chim SS, Tong YK, Chiu RW(2005): Detection of the placental epigenetic signature of 1475314758 . the maspin gene in maternal plasma. Proc Natl Acad Sci USA; 102

8-Genet Banerjee M and Misra D(2013): fetal nucleic acids in maternal circulation: a genetic resource for noninvasive prenatal diagnosis. ISRN;2012.

9-Vichinsky EP (2005): Changing patterns of thalassemia worldwide. Ann N Y Acad Sci, 1054:18-24.

10-Rivella S (2012): The role of ineffective erythropoiesis in non-transfusion dependent thalassemia. Blood Rev.;26 (1 Suppl): S12-5.

11-Camaschella C, Pagani A, Nai A, Silvestri L (2016): The mutual control of iron and erythropoiesis. Int $\mathrm{J}$ Lab Hematol;38(suppl 1):20-26.

12-Chen M, Loh SF, Yu SL (2015): Rapid and reliable pre-implantation genetic diagnosis of common hemoglobin Bart's 
hydrops fetalis syndrome and hemoglobin $\mathrm{H}$ disease determinants using an enhanced single-tube decaplex polymerase chain reaction assay. Am $\mathbf{J}$ Hematol;90: E194-6.

13-Stamatoyannopoulos G (2005): Control of globin gene expression during development and erythroid differentiation Experimental hematology Mar;33(3):259-71.

14-Thein SL (2005): Pathophysiology of $\beta$ thalassemia-A guide to molecular therapies. American Society of Hematology

15-Origa and Raffaella (2017): betathalassemia Genet Med. Jun;19(6):609619.

16-Palstra RJ, de Laat W, Grosveld F (2008): Beta-globin regulation and longrange interactions. AdvGenet.;61:10742. PubMed PMID: 18282504

17-Chan OT, Westover KD, Dietz L (2010): Comprehensive and efficient HBB mutation analysis for detection of $\beta$-hemoglobinopathies in a pan-ethnic population. Am J Clin Pathol.;133:700707.

18-Thein SL (2017): Blood Cells, Molecules, and Diseaseshttp://dx.doi.org/10.1016/j.bcm d.2017.06.001

19-Craig JE, Kelly SJ, Barnetson $\mathrm{R}$ and Thein SL (1992): Molecular characterization of a novel $10.3 \mathrm{~kb}$ deletion causing beta-thalassemia with unusually high $\mathrm{Hb} \mathrm{A} 2$. British journal of hematology.;82(4):735-44.

21- Zhou D, Liu K, Sun CW, Pawlik KM, Townes TM (2010): KLF1 regulates BCL11A expression and gamma- to beta-globin gene switching. Nature genetics. Sep;42(9):742-44.

22-Thein SL (2013): The molecular basis of beta-thalassemia. Cold Spring Harb Perspect Med.;3(5):3.
23-Giordano PC (2013): Strategies for basic laboratory diagnostics of the hemoglobinopathies in multi-ethnic societies: interpretation of results and pitfalls. Int J Lab Hematol;35:465-79.

24-Sabbath DE, Bender MA, Sankaran VG (2016): Characterization of deletions of the HBA and HBB loci by array comparative genomic hybridization. J Mol Diagn.;18:92-99.

25-Borbely N, Phelan L and Szydlo R (2013): Capillary zone electrophoresis for hemoglobinopathy diagnosis. J Clin Pathol;66:29-39.

26- Wang W, Kham SK, Yeo GH (2003): Multiplex minisequencing screen for common Southeast Asian and Indian $\beta$ thalassemia mutations. Clin Chem.;49:209-218

27-Barrett AN (2016): Thalassaemia screening and confirmation of carriers in parents, Best Practice \& Research Clinical Obstetrics and Gynaecology http://dx.doi.org/

10.1016/j.bpobgyn.2016.10.015.

28-Kinnings SL, Geis JA, Almasri E (2015): Factors affecting levels of circulating cell-free fetal DNA in maternal plasma and their implications for non-invasive prenatal testing. Prenat Diagn;35:816-22.

29-Allen S, Young E, Bowns, B (2017): Non-invasive prenatal diagnosis for single-gene disorders.Curr Opin Obstet Gynecol 2017, 29:73-79.

30-Mahboubeh Ramezanzadeh, R. Salehi, M.Farajzadegan, Z.Kamali, S., Salehi (2015): Detection of paternally inherited fetal point mutations for betathalassemia in maternal plasma using simple fetal DNA enrichment protocol with or without whole genome amplification: an accuracy assessment $\mathbf{J}$ Matern Fetal Neonatal Med.

31-Porreco RP, Garite TJ, Maurel K, Marusiak B, Ehrich M, van den Boom 
D, Deciu C and Bombard A (2014): Non-invasive prenatal screening for fetal trisomies 21, 18, 13 and the common sex chromosome aneuploidies from maternal blood using massively parallel genomic sequencing of DNA. Am JObstet Gynecol;211:365.e361-312.

32-Wang E, Batey A, Struble C, Musci T, Song K, Oliphant A (2013): Gestational age and maternal weight effects on fetal cell-free DNA in maternal plasma. Prenat Diagn;33:662-6.

33-Lo YM, Lo ES, Watson N (2017): Twoway cell traffic between mother and fetus: biologic and clinical implications. Blood 1996;88(11):4390-5.

34-Papasavva $\mathrm{T}$, van IJckenWFJ, Kockx CEM(2013): Next-generation sequencing of SNPs for non-invasive prenatal diagnosis: challenges and feasibility as illustrated by an application to b-thalassemia. Eur J Hum Genet 21:1403-14.

35-Greene DN, Pyle AL, Chang JS ( 2012): Comparison of Serbia Capillarys Flex capillary electrophoresis with the BioRad Variant II high-pressure liquid chromatography in the evaluation of hemoglobinopathies. Clin Chim Acta;413:1232-8.

36-Hudecova I and Chiu RWK (2016): Non-invasive prenatal diagnosis of thalassemias using maternal plasma cellfree DNA, Best Practice \& Research Clinical Obstetrics \& Gynaecology, doi: 10.1016/j.bpobgyn.2016.10.016.

37-Chan KCA, Ding C, Gerovassili A, Yeung SW, Chiu RWK and Leung TN (2006): Hypermethylated RASSF1A in maternal plasma: A universal fetal DNA marker that improves the reliability of non-invasive prenatal diagnosis. Clin Chem.;52(12):2211-8.

38-Perlado S, Bustamante-Aragon_es A, Donas M (2016): Fetal genotyping in maternal blood by digital PCR: towards
NIPD of monogenic disorders independently of parental origin. PLoS One; 11:e0153258.

39-Xiong L.Barrett, A. N.Hua, R.Ho, S.Jun, L.Chan, K.Mei, Z, Choolani, M (2018): Non-invasive prenatal testing for the fetal inheritance of maternal betathalassemia mutations using targeted sequencing and relative mutation dosage: a feasibility study: BJOG: 125; 461-468.

40-Barrett AN, McDonnell TC, Chan KC, Chitty LS (2012): Digital PCR analysis of maternal plasma for non-invasive detection of sickle cell anemia. Clin Chem.;58(6):1026-32.

41-Tsui NBY, Kadir RA, Chan KCA, Chi C, Mellars G, Tuddenham EG (2011): Non-invasive prenatal diagnosis of hemophilia by microfluidics digital PCR analysis of maternal plasma DNA. Blood.;117(13):3684-91.

42-Gu W, Koh W, Blumenfeld YJ, ElSayed YY, Hudgins L, Hintz SR (2014): Non-invasive prenatal diagnosis in a fetus at risk for methylmalonic acidemia. Genet Med.;16(7):564-7.

43-Lo YMD, Chan KCA, Sun H, Chen EZ, Jiang P, Lun FMF (2010): Maternal plasma DNA sequencing reveals the genome-wide genetic and mutational profile of the fetus. SciTransl Med.;2(61):61ra91.

44-New MI, Tong YK, Yuen T, Jiang P, Pina C, Chan KC (2014): Non-invasive prenatal diagnosis of congenital adrenal hyperplasia using cell-free fetal DNA in maternal plasma. JClin Endocrinol Metab.;99(6): E1022-30.

45-Hui L and Bianchi DW (2017): Noninvasive prenatal DNA testing: the vanguard of genomic medicine. Annu Rev Med;68:459-72.

46-Chiu RWK, Lau TK, Cheung PT, Gong ZQ, Leung TN, Lo YMD (2002): Noninvasive prenatal exclusion of congenital 
adrenal hyperplasia by maternal plasma analysis: a feasibility study.Clin Chem.;48(5):778-80.

47-Galbiati S, Brisci A, Lalatta F, Seia M, Makrigiorgos GM and Ferrari M (2011): Full COLD-PCR protocol for noninvasive prenatal diagnosis of genetic diseases. Clin Chem.;57(1):136-8.

48-Liu S, Chen L, Zhang X, Li J, Lin H, Liu L (2015): Primer-introduced restriction analysis polymerase chain reaction method for non-invasive prenatal testing of betathalassemia.Hemoglobin.;39(1):18-23.
49-Lun FMF, Tsui NBY, Chan KCA, Leung TY, Lau TK, Charoenkwan $\mathrm{P}$ (2008): Non-invasive prenatal diagnosis of monogenic diseases by digital size selection and relative mutation dosage on DNA in maternal plasma. Proc Natl Acad Sci U S A.; 105(50):19920-5.

50-Lam KW, Jiang P, Liao GJ, Chan KC, Leung TY, Chiu RWK (2012): Noninvasive prenatal diagnosis of monogenic diseases by targeted massively parallel sequencing of maternal plasma: application to betathalassemia. Clin Chem.;58(10):146775. 